\title{
Catanionic Mixtures Forming Gemini-like Amphiphiles
}

\author{
Hideki Sakai ${ }^{1}$, Yuji Okabe ${ }^{1}$, Koji Tsuchiya $^{2}$, Kenichi Sakai ${ }^{1 *}$ and Masahiko Abe ${ }^{1 *}$ \\ ${ }^{1}$ Department of Pure and Applied Chemistry, Faculty of Science and Technology, Tokyo University of Science (2641 Yamazaki, Noda, Chiba \\ 278-8510, JAPAN) \\ ${ }^{2}$ Department of Applied Chemistry, Faculty of Science, Tokyo University of Science (1-3 Kagurazaka, Shinjuku, Tokyo 162-8601, JAPAN)
}

\begin{abstract}
The properties of aqueous mixtures of cationic species with alkyl dicarboxylic acid compounds have been studied. The cationic compounds used in this study were tertiary amine-type $N$-methyl- $N$ - $(2,3-$ dioxypropyl)hexadecylamine (C16amine) and quaternary ammonium-type $N, N$-dimethyl- $N$-(2,3dioxypropyl)hexadecylammonium chloride (C16Q). The alkyl dicarboxylic acid compounds used were $\mathrm{HOOC}\left(\mathrm{CH}_{2}\right)_{10} \mathrm{COOH}(\mathrm{C12H})$ and its sodium salt $(\mathrm{C12Na})$. Three aqueous mixtures were examined in this study: (System I) C16amine + C12H, (System II) C16Q + C12Na, and (System III) C16Q + C12H. The solution pH was set at 12 for System III. The combination of ${ }^{1} \mathrm{H}-\mathrm{NMR}$ and mass spectroscopy data has suggested that a stoichiometric complex is formed in the aqueous solutions at a mole fraction of $\mathrm{C12H}$ (or $\mathrm{C12Na}$ ) $=0.33$. Here, the $\mathrm{C} 12 \mathrm{H}$ (or $\mathrm{C} 12 \mathrm{Na}$ ) molecule added to the system bridges two cationic molecules, like a spacer of gemini surfactants. In fact, the static surface tensiometry has demonstrated that the stoichiometric complex behaves as gemini-like amphiphiles in aqueous solutions. Our current study offers a possible way for easily preparing gemini surfactant systems.
\end{abstract}

Key words: gemini surfactant, catanionic surfactant, alkylamine, alkyl dicarboxylic acid, surfactant mixture

\section{INTRODUCTION}

Gemini surfactants are dimers of monomeric surfactants linked with a spacer at the level of hydrophilic headgroups. The properties of aqueous solutions of gemini surfactants from the physicochemical aspect have been reviewed in earlier literature $^{1-3)}$. One of the key properties of gemini surfactants is their remarkably low critical micelle concentration ( $\mathrm{cmc}$ ) in aqueous media, which enables us to reduce total consumption of surfactants in water-borne chemical products. Gemini surfactants are, therefore, called "environmentally friendly green materials". Unfortunately, however, the synthesis and subsequent purification process of gemini surfactants is generally more complicated than that of conventional monomeric surfactants. This causes difficulties in developing novel gemini surfactants as well as in finding applications for them in the formulation of high-performance chemical products in the fields of cosmetics, personal care, and in medical applications. Although we have recently developed a wide variety of oleic acid-based gemini surfactants through relatively simple chemical reactions to achieve cost-effective syntheses ${ }^{4-7)}$, it is still necessary to find an effective way to formulate gemini surfactants.

On the basis of this background, we propose an alternative method for the easy preparation of new gemini surfac- tant systems by using aqueous mixtures of a cationic compound (either an alkylamine or a quaternary ammoniumtype cationic surfactant) with an alkyl dicarboxylic acid. The physicochemical properties of the aqueous mixtures of alkylamine with alkyl monocarboxylic acid have been studied from the standpoint of their phase behaviors ${ }^{8-10}$. The key conclusion in these studies is that a proton transfer from the acid to the amine results in the aqueous surfactant properties, i.e., we can see various surfactant-like phases such as hexagonal, cubic, and lamellar phases in their ternary phase diagrams with water. These phase behaviors are largely dependent not only on the chain length of the acid and the amine but also on the balance of the chain lengths ${ }^{8-10)}$. A number of studies have focused on the aqueous properties of cationic-anionic mixed surfac$\operatorname{tants}^{11)}$. Such mixtures are sometimes called "catanionic surfactants".

The use of alkyl dicarboxylic acid instead of alkyl monocarboxylic acid may provide an opportunity to develop gemini-like surfactants in aqueous media as a result of mixing with a cationic species. A similar concept has been reported previously ${ }^{12-14)}$. For example, it has been suggested that an alkylamine compound with sugar moieties forms a stoichiometric complex with alkyl dicarboxylic acid when mixed at a molar ratio of 2:1 in aqueous solutions ${ }^{12}$.

\footnotetext{
*Correspondence to: Kenichi Sakai and Masahiko Abe, Department of Pure and Applied Chemistry, Faculty of Science and Technology, Tokyo University of Science, 2641 Yamazaki, Noda, Chiba 278-8510, JAPAN

E-mail: k-sakai@rs.noda.tus.ac.jp, abemasa@rs.noda.tus.ac.jp

Accepted June 15, 2011 (received for review May 24, 2011)

Journal of Oleo Science ISSN 1345-8957 print / ISSN 1347-3352 online

http://www.jstage.jst.go.jp/browse/jos/ http://mc.manusriptcentral.com/jjocs
} 
The aqueous solution mixtures of an alkyl monocarboxylic acid and a bola-type alkyldiamine have also been studied, where the amine compound bridges two acid molecules, like a spacer of gemini surfactants ${ }^{13)}$. These studies are quite interesting but a physicochemical understanding of such aqueous mixtures is still not enough, particularly in the region of low concentrations. We believe that the dilute aqueous solution properties are important for characterizing the stoichiometric complex systems as gemini surfactants.

In this study, we have characterized the aqueous mixtures of cationic species with alkyl dicarboxylic acid. The aim of this study is to demonstrate whether the mixtures behave as gemini-like amphiphiles in their dilute aqueous solutions. The cationic compounds employed in this study were $N$-methyl- $N$ - (2,3-dioxypropyl) hexadecylamine (C16amine) and $N, N$-dimethyl- $N$ - (2,3-dioxypropyl) - hexadecylammonium chloride(C16Q). The chemical structures are shown in Fig. 1. We expect that the glycerin unit covalently bound to the amine or quaternary ammonium headgroup results in increased water solubility (compared with glycerin-unmodified compounds, such as $N, N$-dimethylhexadecylamine or hexadecyltrimethylammonium chloride) and hence allows highly hydrophilic stoichiometric complex systems to form, which do not precipitate even at an equivalent molar mixing with alkyl dicarboxylic acid. This expectation is supported by the experimental results in which the glycerin-modified cationic surfactant (C16Q) narrows the precipitation region in its three-phase diagram with an anionic surfactant and water and the catanionic surfactants form vesicular assemblies which are well-dispersed in aqueous media ${ }^{15}$. The alkyl dicarboxylic acid compounds reported herein were bola-type, as shown in Fig. 1, and the number of methylene units was fixed at ten as a typical example. Hereafter we call the alkyl dicarboxylic acid compounds "C12H" and "C12Na".

\section{EXPERIMENTAL PROCEDURES}

\subsection{Materials}

$\mathrm{C} 12 \mathrm{H}$ was purchased from Wako. C12Na was obtained through the ion exchange of the $\mathrm{C} 12 \mathrm{H}$ sample. For the synthesis of C16amine, we used the following chemicals: 3-methylamino-1,2-propanediol(Wako), 1-bromohexadecane (Tokyo Chemical Industry, TCI), sodium hydroxide (Wako), and methanol(Wako). These chemicals were of analytical grade and used without further purification. The cationic surfactant (C16Q) was synthesized according to the procedure mentioned in our previous paper ${ }^{15}$. The water used in this study was deionized with a Barnstead NANO Pure Diamond UV system and filtered with a Millipore membrane filter $(0.22 \mu \mathrm{m}$ pore size $)$.

\subsection{Synthesis and molecular characterization of C16amine}

C16amine was synthesized according to the reaction scheme shown in Fig. 1. 3-methylamino-1,2-propanediol ( $10.5 \mathrm{~g}, 0.1 \mathrm{~mol})$ was mixed with 1-bromohexadecane (10.1 $\mathrm{g}, 0.033 \mathrm{~mol})$ in methanol, and then the mixture was reacted for $24 \mathrm{~h}$ at $80^{\circ} \mathrm{C}$ under magnetic stirring. After evaporation of the reaction solvent, sodium hydroxide $(4 \mathrm{~g}$, $0.1 \mathrm{~mol}$ ) was added to the residue in the presence of water. The aqueous mixture was refluxed for $12 \mathrm{~h}$ at ca. $90^{\circ} \mathrm{C}$, and then cooled to room temperature. Hot-filtration was performed five times to rinse the crude product, then the product was dried under a reduced pressure. The yield was $89 \%$. The final product was characterized with analytical techniques which included ${ }^{1} \mathrm{H}-\mathrm{NMR}$ (JEOL-ECP $500 \mathrm{MHz}$ ) and ESI-MS (FT-ICR MS Varian 910-MS) spectroscopies, and elemental analysis (PerkinElmer 2400 Series II CHNS/O Analyzer). The characterization data are shown below.

${ }^{1} \mathrm{H}-\mathrm{NMR}\left(\mathrm{CDCl}_{3}\right): \delta$ 0.87-0.89(t, 3H, $\left.\mathrm{CH}_{3}\right), 1.26(\mathrm{~s}, 28 \mathrm{H}$, $\left.14 \mathrm{CH}_{2}\right), 1.43-1.48\left(\mathrm{q}, 2 \mathrm{H}, \mathrm{CH}_{2} \mathrm{CH}_{2} \mathrm{~N}\right), 2.27-2.59(\mathrm{~m}, 7 \mathrm{H}$, $\left.\mathrm{CH}_{3} \mathrm{NCH}_{2} \mathrm{CH}(\mathrm{OH}) \mathrm{CH}_{2} \mathrm{OH}\right), 3.48-3.51\left(\mathrm{q}, 1 \mathrm{H}, \mathrm{NCH}_{2} \mathrm{CH}(\mathrm{OH})\right.$ $\left.\mathrm{CH}_{2} \mathrm{OH}\right)$, and 3.73-3.79 ppm $\left(\mathrm{m}, 2 \mathrm{H}, \mathrm{CH}(\mathrm{OH}) \mathrm{CH}_{2} \mathrm{OH}\right)$.

ESI-MS: $[\mathrm{M}+\mathrm{H}]^{+} 330.35$ (Calc. 330.41).

Elemental analysis: Found (Calc.) C: 73.16 (72.89), H: 13.28 (13.15), and N: 4.20(4.25).

\subsection{Physicochemical analysis}

Static surface tension measurements were performed by using a Krüss K100C Wilhelmy auto surface tensiometer with a platinum plate. Continuous measurements were carried out until a change in the surface tension was

$$
\mathrm{C}_{16} \mathrm{H}_{33} \mathrm{Br}+\mathrm{CH}_{3} \mathrm{NH}\left(\mathrm{CH}_{2} \mathrm{CHOHCH}_{2} \mathrm{OH}\right) \longrightarrow \mathrm{C}_{16} \mathrm{H}_{33} \mathrm{~N}\left(\mathrm{CH}_{3}\right)\left(\mathrm{CH}_{2} \mathrm{CHOHCH}_{2} \mathrm{OH}\right)
$$

$\begin{array}{clc}\mathrm{HOOC}\left(\mathrm{CH}_{2}\right)_{10} \mathrm{COOH} & \mathrm{C} 12 \mathrm{H} & \mathrm{C}_{16} \mathrm{H}_{33} \mathrm{~N}^{+}\left(\mathrm{CH}_{3}\right)_{2}\left(\mathrm{CH}_{2} \mathrm{CHOHCH}_{2} \mathrm{OH}\right) \mathrm{Cl}^{-} \\ \mathrm{NaOOC}\left(\mathrm{CH}_{2}\right)_{10} \mathrm{COONa} & \mathrm{C} 12 \mathrm{Na} & \mathrm{C} 16 \mathbf{Q}\end{array}$

Fig. 1 Chemical structures of C16amine, C16Q, C12H, and C12Na. The synthetic route of C16amine is also shown here. 
reduced to less than $0.01 \mathrm{mN} \mathrm{m}^{-1}$ per $90 \mathrm{~s}$.

Unless otherwise stated, all measurements reported herein were performed at $25^{\circ} \mathrm{C}$ (or at a room temperature of ca. $25^{\circ} \mathrm{C}$ ).

\section{RESULTS AND DISCUSSION}

Three aqueous mixtures were examined in this study: (System I) C16amine + C12H, (System II) C16Q + C12Na, and (System III) C16Q $+\mathrm{C} 12 \mathrm{H}$. The solution $\mathrm{pH}$ was set at 12 for System III by using an aqueous solution of $100 \mathrm{mmol}$ $\mathrm{dm}^{-3} \mathrm{NaOH}$. No additional electrolytes were added to the three systems. Under these experimental conditions, neither precipitation nor phase separation was seen for Systems II and III, at least up to the total concentration of

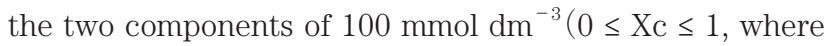
$\mathrm{Xc}$ is the mole fraction of $\mathrm{C} 12 \mathrm{H}$ or $\mathrm{C} 12 \mathrm{Na}$ ).

Figure 2 shows the visual appearance of the C16amine and $\mathrm{C} 12 \mathrm{H}$ mixtures in aqueous solutions (System I). The total concentration of the two components was fixed at 10 mmol dm ${ }^{-3}$ and the mole fraction of the components was varied. The solubility of C16amine in water is less than 10 mmol dm ${ }^{-3}$ at $25^{\circ} \mathrm{C}$ and hence a cloudy solution with some suspended aggregates was obtained for the single $\mathrm{C} 16$ amine system $(\mathrm{Xc}=0)$. An increased mole fraction of $\mathrm{C} 12 \mathrm{H}$ resulted in the disappearance of the suspended aggregates but the sample solution prepared at $\mathrm{Xc}=0.1$ was still cloudy. Interestingly, the sample solutions became transparent in the range of $0.2 \leq \mathrm{Xc} \leq 0.33$, without any precipitants. In particular, the sample solution prepared at $\mathrm{Xc}=0.33$ exhibited the most significant foaming capability among the sample solutions obtained in System I. This indicates that $\mathrm{Xc}=0.33$ is a key mole fraction for studying the aqueous C16amine and $\mathrm{C} 12 \mathrm{H}$ mixtures. It is obvious that this mole fraction corresponds to the optimum charge neutralization point if the stoichiometric complex formation occurs between the two components. The poor solubility of $\mathrm{C} 12 \mathrm{H}$ in water resulted in precipitation in the range of $0.5 \leq \mathrm{Xc} \leq 1$.

In order to confirm the complex formation between the cationic species and the alkyl dicarboxylic acid compounds, nano-ESI-MS and ${ }^{1} \mathrm{H}-\mathrm{NMR}$ spectroscopy measurements were performed at a fixed Xc $=0.33$. Similar ESI-MS analyses have been reported by Blanzat et al., where the stoichiometric complex formation was suggested to have occurred for the mixture of alkylamine and alkyl dicarboxylic acid compounds ${ }^{12)}$. Nano-ESI-MS spectra are shown in Fig. 3 for the C16amine $+\mathrm{C} 12 \mathrm{H}$ mixture (System I) and the $\mathrm{C} 16 \mathrm{Q}+\mathrm{C} 12 \mathrm{Na}$ mixture (System II). The $\mathrm{m} / \mathrm{z}$ values calculated for [the stoichiometric complex $+\mathrm{H}]^{+}$are 889.89 and 917.92. In this figure, it is possible to see the corresponding peaks at $889.90 \mathrm{~m} / \mathrm{z}$ for System I and at $917.76 \mathrm{~m} / \mathrm{z}$ for System II, which are quite consistent with the calculated

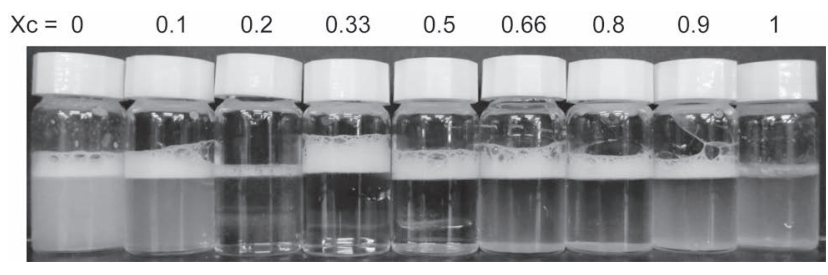

Fig. 2 Visual appearance of aqueous mixtures of C16amine and $\mathrm{C} 12 \mathrm{H}$ (System I). The total concentration of the two components is fixed at $10 \mathrm{mmol} \mathrm{dm}^{-3}$ and the mole fraction of $\mathrm{C} 12 \mathrm{H}$ is varied from 0 to 1 . $\mathrm{C} 16 \mathrm{amine}$ and $\mathrm{C} 12 \mathrm{H}$ were added to the pure water in the sample vials, and then the samples were mixed under ultrasonic irradiation for $2 \mathrm{~h}$ and finally equilibrated in a water-shaker bath for $12 \mathrm{~h}$. These pictures were taken after gentle hand-shaking.

$\mathrm{m} / \mathrm{z}$ values. This is good evidence that gemini-like stoichiometric complex molecules are present in the bulk solution, as expected. We note that it was not possible to perform nano-ESI-MS spectroscopy measurements for System III because of its high electrolyte concentration and its highly alkaline nature.

Further evidence regarding the formation of the geminilike complex was suggested on the basis of ${ }^{1} \mathrm{H}-\mathrm{NMR}$ data. These ${ }^{1} \mathrm{H}$-NMR measurements were performed in $\mathrm{D}_{2} \mathrm{O}$ in the presence of sodium (3-trimethylsilyl)-1-propanesulfonate as an NMR standard reagent. In the case of System III, $\mathrm{NaOD}$ was used for the $\mathrm{pH}$ adjustment. The poor solubility of $\mathrm{C} 16$ amine $(\mathrm{Xc}=0)$ and $\mathrm{C} 12 \mathrm{H}(\mathrm{Xc}=1)$ in water caused difficulties in measuring their ${ }^{1} \mathrm{H}-\mathrm{NMR}$ spectra (System I), so only Systems II and III were examined here. In these systems, we could measure their ${ }^{1} \mathrm{H}-\mathrm{NMR}$ spectra at $\mathrm{Xc}=0$ and 1 and hence see any shifts of characteristic signals when $\mathrm{C} 16 \mathrm{Q}$ was mixed with $\mathrm{C} 12 \mathrm{Na}$ or $\mathrm{C} 12 \mathrm{H}(\mathrm{Xc}=0.33)$. The chemical shifts of the characteristic signals are summarized in Table 1 for Systems II and III. For both systems the mixing resulted in changes in the chemical shift: one can see the decreased chemical shift(i.e., upfield shift) of the characteristic signals assigned as A and B protons (originated from $\mathrm{C} 12 \mathrm{Na}$ or $\mathrm{C} 12 \mathrm{H}$ ) and the slightly increased chemical shift (i.e., downfield shift) of the characteristic signals assigned as d, e, and f protons (originated from C16Q). This suggests a change in the electrostatic field around the $\mathrm{C} 16 \mathrm{Q}$ and $\mathrm{C} 12 \mathrm{H}$ (or C12Na) molecules to occur as a result of their mixing, which supports our hypothesis that the stoichiometric complex is present in the aqueous solutions.

Figure 4 shows the static surface tension data obtained for the three systems as a function of the total concentration of the cationic and anionic species at a fixed $\mathrm{Xc}=0.33$. Also shown here are the surface tension data of aqueous C16Q solutions measured in pure water and at pH 12. For 

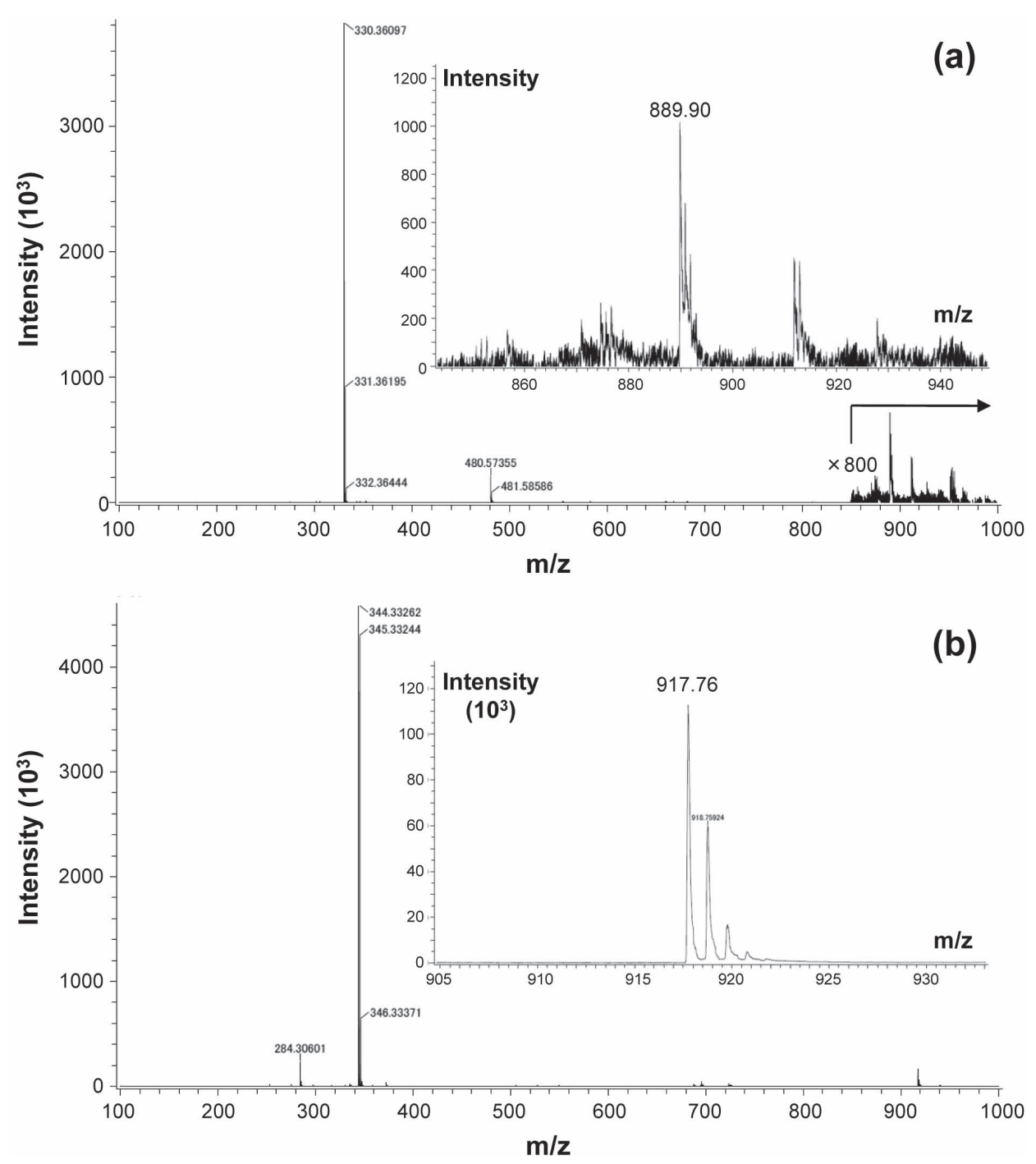

Fig. 3 Nano-ESI-MS spectra of aqueous mixtures of (a) C16amine $+\mathrm{C} 12 \mathrm{H}$ (System I) and (b) C16Q + C12Na (System II).

all the mixtures in regions of low concentrations, the surface tension decreases sharply with increasing concentration and attains a break point. Then the surface tension becomes constant even when the total concentration is increased further at the constant Xc. This is a general trend we can see in aqueous surfactants systems and the concentration corresponding to the break point is assumed to be the cmc of each mixture. Physicochemical parameters estimated on the basis of the static surface tension data are listed in Table 2: cmc, surface tension measured at each cmc $\left(\gamma_{\mathrm{cmc}}\right)$, surface excess concentration estimated at the cmc $\left(\Gamma_{\text {cmc }}\right)$, occupied area per stoichiometric complex molecule adsorbed at the air/aqueous solution interface $\left(A_{\text {cmc }}\right)$, and $\mathrm{p} C_{20}\left(=-\log C_{20}\right.$, where the $C_{20}$ value is defined to be the concentration where a decrease in the surface tension of $20 \mathrm{mN} \mathrm{m}^{-1}$ from pure water is recorded, and therefore, this value is indicative of an efficiency in lowering the surface tension $)^{16)}$. Here the $\Gamma_{\mathrm{cmc}}$ and $A_{\mathrm{cmc}}$ values are calculated according to the following equations ${ }^{16)}$ :

$$
\begin{aligned}
\Gamma_{\mathrm{cmc}} & =-\frac{1}{2.303 i R T}\left(\frac{d \gamma}{d \log C}\right)_{\mathrm{T}} \\
A_{\mathrm{cmc}} & =\frac{1}{N_{A} \Gamma_{\mathrm{cmc}}}
\end{aligned}
$$

where $i$ is the number of adsorption species, $T$ is the absolute temperature, $N_{\mathrm{A}}$ is the Avogadro constant, and $R$ is the gas constant. It is not easy to find accurate $i$ values for catanionic mixtures (especially for Systems I and II), so the $\Gamma_{\mathrm{cmc}}$ and $A_{\mathrm{cmc}}$ values for these systems are not shown in Table 2. We also note here that adjusting the $\mathrm{pH}$ to 12 requires the addition of a small volume of $\mathrm{NaOH}$ aqueous solution into the system, and this necessarily causes an increased background electrolyte concentration. At this $\mathrm{pH}$ the background electrolyte concentration is estimated to be much higher than the resultant $\mathrm{cmc}(\mathrm{s})$, and therefore, 
Table $1{ }^{1} \mathrm{H}-\mathrm{NMR}$ chemical shifts measured for systems II and III.

\begin{tabular}{|c|c|c|c|c|c|c|c|c|}
\hline & $\begin{array}{l}\text { C16Q } \\
\text { (ppm) }\end{array}$ & $\begin{array}{l}\mathrm{C} 12 \mathrm{Na} \\
(\mathrm{ppm})\end{array}$ & $\begin{array}{c}\text { System II } \\
(\mathrm{ppm})\end{array}$ & $\begin{array}{c}\Delta \delta_{\text {II }} \\
(\mathrm{ppm})\end{array}$ & $\begin{array}{c}\mathrm{C}^{\left.26 Q^{*}\right)} \\
(\mathrm{ppm})\end{array}$ & $\begin{array}{c}\left.\mathrm{C} 12 \mathrm{H}^{*}\right) \\
(\mathrm{ppm})\end{array}$ & $\begin{array}{c}\text { System III*) } \\
(\mathrm{ppm})\end{array}$ & $\begin{array}{l}\Delta \delta_{\text {III }}^{*)} \\
(\mathrm{ppm})\end{array}$ \\
\hline $\mathrm{a}$ & $0.81-0.84$ & & $0.81-0.84$ & $\approx 0$ & $0.81-0.83$ & & $0.81-0.83$ & $\approx 0$ \\
\hline $\mathrm{b}$ & $1.25,1.31$ & & $1.24,1.31$ & $\approx 0$ & $1.24,1.31$ & & $1.26,1.31$ & $\approx 0$ \\
\hline $\mathrm{c}$ & 1.72 & & 1.72 & $\approx 0$ & 1.72 & & 1.72 & $\approx 0$ \\
\hline d & $3.32-3.57$ & & $3.34-3.58$ & +0.01 & $3.14-3.54$ & & $3.16-3.55$ & +0.02 \\
\hline $\mathrm{e}$ & $3.14,3.15$ & & $3.15,3.16$ & +0.01 & $3.10,3.11$ & & $3.11,3.13$ & +0.02 \\
\hline $\mathrm{f}$ & $4.19-4.22$ & & $4.21-4.24$ & +0.02 & $4.03-4.08$ & & $4.06-4.10$ & +0.03 \\
\hline A & & $2.13-2.17$ & $2.07-2.09$ & -0.07 & & $2.14-2.17$ & $2.09-2.11$ & -0.06 \\
\hline B & & $1.51-1.54$ & $1.49-1.51$ & -0.03 & & $1.51-1.53$ & $1.48-1.51$ & -0.03 \\
\hline $\mathrm{C}$ & & 1.27 & 1.27 & $\approx 0$ & & 1.27 & 1.26 & -0.01 \\
\hline
\end{tabular}

$\mathrm{HOOC}-\mathrm{CH}_{2}-\mathrm{CH}_{2}-\left(\mathrm{CH}_{2}\right)_{6}-\mathrm{CH}_{2}-\mathrm{CH}_{2}-\mathrm{COOH}$ (or $2 \mathrm{Na}^{+}$)

*) Measured at $\mathrm{BH} 12$.
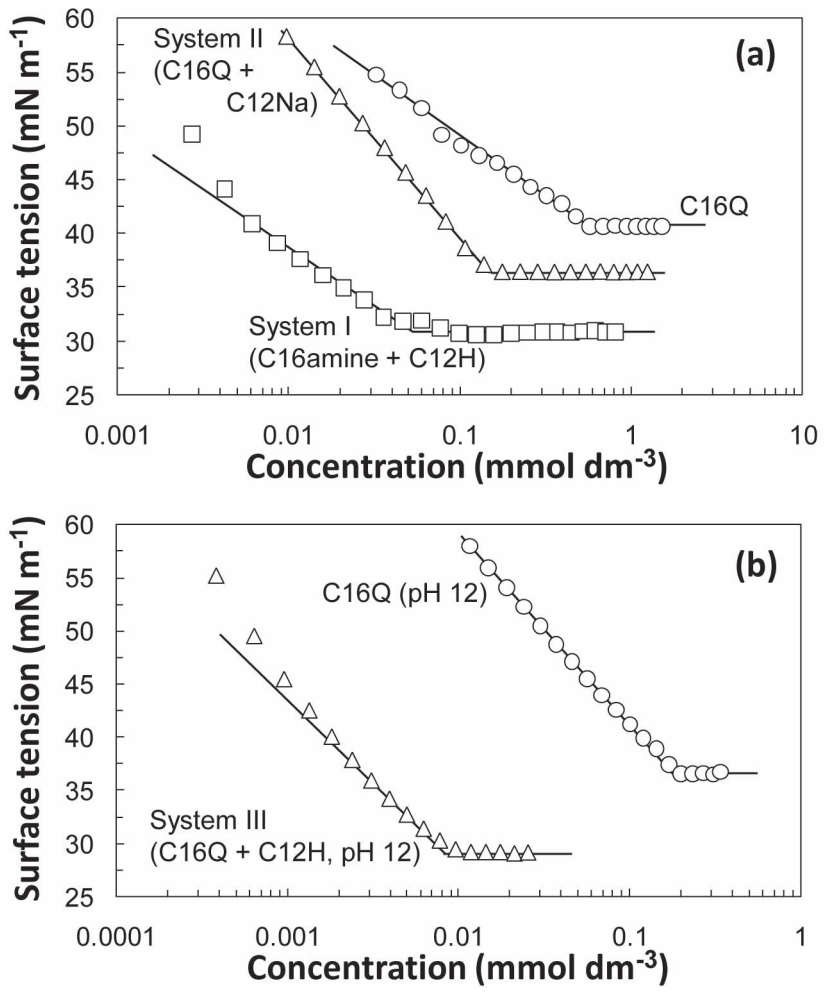

Fig. 4 Static surface tension of aqueous mixtures of (a) C16amine $+\mathrm{C} 12 \mathrm{H}$ (System I) and C16Q $+\mathrm{C} 12 \mathrm{Na}$ (System II) and (b) C16Q + C12H at $\mathrm{pH} 12$ (System III) as a function of the total concentration. The mole fraction of $\mathrm{C} 12 \mathrm{H}$ (or $\mathrm{C} 12 \mathrm{Na}$ ) is fixed at 0.33 . The surface tension data measured for C16Q are also shown in each figure. we assume $i=1$ when calculating the $\Gamma_{\mathrm{cmc}}$ and $A_{\mathrm{cmc}}$ values (whereas, the single C16Q system gives $i=2$ because of its 1:1-type ionic surfactant nature ${ }^{16}$. Clearly, the gemini-like stoichiometric complex formation results in a lower cmc and a lower $\gamma_{\text {cmc }}$ when compared with the monomeric surfactant (C16Q) examined under corresponding experimental conditions. In addition, the $A_{\text {cmc }}$ values estimated for the stoichiometric complex (System III) are less than the $2 \times$ $A_{\text {cmc }}$ values estimated for C16Q at $\mathrm{pH} 12$, suggesting the closer packing of the complex molecules (per a hydrophobic "tail" chain)adsorbed at the air/aqueous solution interface $^{\S)}$. These results confirm the excellent surface activity of the gemini-like stoichiometric complex ${ }^{\S \S)}$. Two reasons must be considered for this surface activity: one is the

8) It was found that a decreased $\mathrm{pH}$ from 12 results in an increased surface tension: at a given total concentration of 1 mmol dm ${ }^{-3}(\mathrm{C} 16 \mathrm{Q}+\mathrm{C} 12 \mathrm{H}$, at $\mathrm{Xc}=0.33)$ in the presence of $100 \mathrm{mmol} \mathrm{dm}{ }^{-3} \mathrm{NaCl}$ as a background electrolyte, the surface tension is measured as $33-34 \mathrm{mN} \mathrm{m}^{-1}$ at $\mathrm{pH} 10-12$, and as $43-44 \mathrm{mN} \mathrm{m}^{-1}$ at $\mathrm{pH}$ 6-8, respectively. It is possible to assume, therefore, that the stoichiometric complex formation in System III preferentially occurs under the alkaline condition, although the exact equilibrium constant between the stoichiometric complex and the free "monomers" is not known.

§ ) We also performed surface tension measurements in System II as a function of Xc. The resultant surface tension data gave $\mathrm{p} C_{20}$ values of 4.6-4.7 in the range of $0.1 \leq \mathrm{Xc} \leq$ 0.67 . These $\mathrm{p} C_{20}$ values are larger than those calculated for the single C16Q system (see Table 2). This indicates that the mixing of the two components $(\mathrm{C} 16 \mathrm{Q}+\mathrm{C} 12 \mathrm{Na})$ in the range of $0.1 \leq \mathrm{Xc} \leq 0.67$, even not at $\mathrm{Xc}=0.33$, results in the complex formation that induces the surface tension lowering. No significant difference in the surface tension lowing capability $\left(\mathrm{p} C_{20}\right)$ was observed, at least in the range of $0.1 \leq \mathrm{Xc} \leq 0.67$. 
Table 2 Summary of static surface tension data.

\begin{tabular}{ccccccc}
\hline & $\begin{array}{c}\mathrm{cmc} \\
\left(\mathrm{mmol} \mathrm{dm}^{-3}\right)\end{array}$ & $\begin{array}{c}\gamma_{\mathrm{cmc}} \\
\left(\mathrm{mN} \mathrm{m}^{-1}\right)\end{array}$ & $\begin{array}{c}\Gamma_{\mathrm{cmc}} \\
\left(\mu \mathrm{mol} \mathrm{m}^{-2}\right)\end{array}$ & $\begin{array}{c}A_{\mathrm{cmc}} \\
\left(\mathrm{nm}^{2}\right)\end{array}$ & $i$ & $\mathrm{p} C_{20}$ \\
\hline C16Q & 0.61 & 40.6 & 0.92 & 1.8 & 2 & 4.3 \\
System II (C16Q + C12Na) & 0.15 & 36.4 & & & & 4.7 \\
System I (C16amine + C12H) & 0.051 & 30.6 & & & & 5.7 \\
C16Q (pH 12) & 0.18 & 36.5 & 3.2 & 0.53 & 1 & 4.6 \\
System III (C16Q + C12H, pH 12) & 0.0081 & 29.2 & 2.9 & 0.57 & 1 & 6.3 \\
\hline
\end{tabular}

"gemini effect" (i.e., the surface activity is generally greater for gemini surfactants than for corresponding monomeric surfactants) and the other is the charge neutralization in our current case.

\section{CONCLUSIONS}

The properties of the aqueous mixtures of a cationic compound (either alkylamine-type C16amine or quaternary ammonium-type C16Q) with an alkyl dicarboxylic acid compound (either $\mathrm{C} 12 \mathrm{H}$ or $\mathrm{C} 12 \mathrm{Na}$ ) have been studied. The alkyl dicarboxylic acid molecules added to the systems play the role of a spacer connecting two cationic molecules. This yields a gemini-like stoichiometric complex in aqueous solutions, which is supported by nano-ESI-MS and ${ }^{1} \mathrm{H}-\mathrm{NMR}$ spectroscopies. The static surface tensiometry has demonstrated the greater surface activity of the gemini-like stoichiometric complex when compared with the monomeric surfactant (C16Q). In particular, it is interesting to note that the two intrinsically surface inactive components (C16amine and $\mathrm{C} 12 \mathrm{H})$ behave as gemini-like amphiphiles as a result of their mixing in aqueous solutions. The mixing of the cationic species with the alkyl dicarboxylic acid compounds is, therefore, a possible way of preparing new gemini surfactant systems. This is a fruitful finding in the field of surfactant chemistry, because the synthesis and purification of gemini surfactants having a covalently bound spacer is generally a hard work.

\section{ACKNOWLEDGEMENTS}

This work was financially supported by MEXT(The Ministry of Education, Culture, Sports, Science and Technology in Japan) Grant-in-Aid for Young Scientists (B) 21750199.

\section{References}

1) Zana, R.; Xia, J. Gemini Surfactants, Synthesis, Interfacial and Solution-Phase Behavior, and Applications (Zana, R.; Xia, J. ed.). Marcel Dekker. New York. Chapter 1(2003).

2) Zana, R. Structure-Performance Relationships in Surfactants (Esumi, K.; Ueno, M. ed.). $2^{\text {nd }}$ edn. Marcel Dekker. New York. Chapter 7 (2003).

3) Zana, R.; Alami, E. Novel Surfactants: Preparation, Applications, and Biodegradability (Holmberg, K. ed.) . Marcel Dekker. New York. Chapter 12 (2003).

4) Sakai, K.; Sakai, H.; Abe, M. Recent advances in gemini surfactants: oleic acid-based gemini surfactants and polymerizable gemini surfactants. J. Oleo Sci. 60, 159-163 (2011).

5) Takamatsu, Y.; Iwata, N.; Tsubone, K.; Torigoe, K.; Endo, T.; Sakai, K.; Sakai, H.; Abe, M. Synthesis and aqueous solution properties of novel anionic heterogemini surfactants containing a phosphate headgroup. J. Colloid Interface Sci. 338, 229-235 (2009).

6) Sakai, K.; Sangawa, Y.; Takamatsu, Y.; Kawai, T.; Matsumoto, M.; Sakai, H.; Abe, M. Sulfonic-hydroxyl-type heterogemini surfactants synthesized from unsaturated fatty acids. J. Oleo Sci. 59, 541-548(2010).

7) Sakai, K.; Umemoto, N.; Matsuda, W.; Takamatsu, Y.; Matsumoto, M.; Sakai, H.; Abe, M. Oleic acid-based gemini surfactants with carboxylic acid headgroups. $J$. Oleo Sci. 60, 411-417(2011).

8) Backlund, S.; Friman, R.; Karlsson, S. Aggregation studies in alkanoic acid-alkylamine-water systems. Colloids Surf. A 123-124, 125-133(1997).

9) Karlsson, S.; Friman, R.; Björkqvist, M.; Lindström, B.; Backlund, S. Phase behavior and characterization of the system acetic acid-dodecylamine-water. Langmuir 17, 3573-3578(2001).

10) Karlsson, S.; Friman, R.; Lindström, B.; Backlund, S. Self-assembly in the system decanoic acid-butylaminewater. J. Colloid Interface Sci. 243, 241-247 (2001).

11) Hao, J.; Hoffmann, H. Self-assembled structures in excess and salt-free catanionic surfactant solutions. Curr. Opinion Colloid Interface Sci. 9, 279-293 (2004).

12) Blanzat, M.; Perez, E.; Rico-Lattes, I.; Prome, D.; 
Prome, J. C.; Lattes, A. New catanionic glycollipids. 1. Synthesis, characterization, and biological activity of double-chain and gemini catanionic analogues of galactosylceramide (gal $\beta_{1}$ cer) . Langmuir 15, 6163-6169 (1999).

13) Douliez, J.-P.; Navailles, L.; Nallet, F. Self-assembly of fatty acid-alkylboladiamine salts. Langmuir 22, 622-627 (2006).

14) Shankar, B. V.; Patnaik, A. Chiral cones and vesicles from gemini-type fatty acid-heteroditopic amine mixtures. Soft Matter 4, 1713-1717 (2008).

15) Tsuchiya, K.; Ishikake, J.; Kim, T. S.; Ohkubo, T.; Sakai, H.; Abe, M. Phase behavior of mixed solution of a glycerin-modified cationic surfactant and an anionic surfactant. J. Colloid Interface Sci. 312, 139-145(2007).

16) Rosen, M. J. Surfactants and Interfacial Phenomena. $3^{\text {rd }}$ edn. John Wiley \& Sons Ltd. New York (2004). 